\title{
Cell cycle arrest and differentiation induction by 5,7-dimethoxycoumarin in melanoma cell lines
}

\author{
DANIELA ALESIANI ${ }^{1 *}$, ROSELLA CICCONI ${ }^{2 *}$, MAURIZIO MATTEI $^{1,2}$, \\ CARLA MONTESANO ${ }^{2}$, ROBERTO BEI ${ }^{3}$ and ANTONELLA CANINI ${ }^{1}$ \\ ${ }^{1}$ Department of Biology, University of Rome 'Tor Vergata', Via della Ricerca Scientifica; \\ ${ }^{2}$ Centro di Servizi Interdipartimentale Stazione per la Tecnologia Animale (STA), and ${ }^{3}$ Department of Experimental \\ Medicine and Biochemical Sciences, University of Rome 'Tor Vergata', Via Montpellier, 1-00133 Rome, Italy
}

Received May 11, 2007; Accepted July 14, 2007

\begin{abstract}
In the present study we investigated the antiproliferative activity of 5,7-dimethoxycoumarin on the murine B16 and human A375 melanoma cell lines. The inhibitory concentration $50\left(\mathrm{IC}_{50}\right)$ was estimated for each cell line by preliminary assay of tetrazolium salt reduction (MTT). With Trypan blue exclusion test we detected a cytostatic but not cytotoxic effect of the treatment in melanoma cells: 5,7dimethoxycoumarin significantly reduced cell proliferation in a time- and dose-dependent manner, blocking the cell cycle in the $\mathrm{G}_{0} / \mathrm{G}_{1}$ phase both in B16 and A375 cells. Melanoma growth reduction was coupled to a differentiation process detected by monitoring some specific markers: i) morphological changes with development of dendrite-like projections from the cell surface; ii) melanin synthesis; and iii) PpIX accumulation. Induction of the differentiation process was more significant in murine melanoma cells, where the treatment irreversibly reduced cell growth. Consistent with $\mathrm{G}_{0} / \mathrm{G}_{1}$ arrest and melanogenesis in B16 cells, 5,7-dimethoxycoumarin strongly decreased activation of the mitogen-activated protein kinase extracellular signal-related kinase $1 / 2$, which is upregulated in many types of cancer. These findings suggest that 5,7-dimethoxycoumarin should be further investigated through studies both in vitro, to identify the binding partners for this compound, and in preclinical animal models.
\end{abstract}

\section{Introduction}

Coumarins are a class of compounds widely distributed in plants (1) and showing low toxicity in the human body (2).

Correspondence to: Professor A. Canini, Department of Biology, University of Rome 'Tor Vergata', Via della Ricerca Scientifica, 1-00133 Rome, Italy

E-mail: canini@uniroma2.it

${ }^{*}$ Contributed equally

Key words: 5,7-dimethoxycoumarin, antiproliferative activity, melanoma differentiation, phospho-extracellular signal-regulated kinase $1 / 2$
They possess several biological activities such as anti-bacterial (3), anti-platelet $(4,5)$ vasodilatatory $(6,7)$, anti-asthmatic (8), anti-mutagenic (9), and anti-inflammatory (10). They also protect against oxidative damage and exhibit antitumourigenic activity (11-14). Coumarins and their derivative compounds have been used in clinical treatment, alone or in combination therapy, of various malignant cancers, such as renal, lung and kidney carcinoma and malignant melanoma (15). Various in vitro data showed antineoplastic activity of these compounds, such as 7-hydroxycoumarin against lung adenocarcinoma and other cell lines (16-19), the synthetic 6-nitro-7-hydroxycoumarin against renal and melanoma cell lines (20-22), esculetin against human leukemia cells (23), decursin against human prostate carcinoma cells (24), and daphnetin against human renal carcinoma cells (22).

A coumarin derivative, 5,7-dimethoxycoumarin, has been identified in a small group of vegetable species, including Euodia borbonica L. var. borbonica (25), Citrus limon L. (26), Citrus bergamia L. (27), Heracleum mantegazzianum L. (28), Citrus medica L. var. sarcodactylis (29) and Carica papaya L. (30). This molecule showed both a differentiating effect on the HL-60 cell line (27) and an inhibition activity in DNA adduct formation, induced by carcinogens, in mouse mammary gland (31).

The differentiation process still represents a crucial point in development and progression of many cancer types, such as melanoma, which show also alterations in the normal cell growth program and survival time (32). In such a scenario mitogen-activated protein kinases (MAPKs, serine threonine kinases) seem to play an important role by Ras/Raf/MEK/ERK pathway controlling cellular processes such as differentiation, proliferation and death (33). Moreover, some proto-oncogenes, involved in tumor development and progression, encode proteins of the Ras/Raf/MEK/ERK pathway which are constitutively activated in the growth process of several types of cancer (34).

Since research in melanoma cancer therapy is focused on the discovery of novel drugs able to reduce its proliferative capacity and induce terminal differentiation (35), in this study we have investigated the antiproliferative activity of 5,7-dimethoxycoumarin in murine B16 and human A375 melanoma cell lines, specific markers of melanoma cell 
differentiation and the expression level of extracellular signalrelated kinase (ERK) 1/2 after treatment.

\section{Materials and methods}

Test compound. Synthetic 5,7-dimethoxycoumarin was purchased from Sigma-Aldrich (116238). The compound was dissolved in methanol and a solution with a concentration of $20 \mathrm{mM}$ was obtained. In the treatment of cells, a volume of this solution was added to culture medium and its percentage with respect to the medium was $0.5,1.25$ and $2.5 \%$ for 100 , 250 and $500 \mu \mathrm{M}$, respectively.

Cell lines and culture conditions. Cell lines used in this study were murine melanoma B16 F1, human melanoma A375, human breast adenocarcinoma MCF7, human prostate adenocarcinoma PC3, and human colorectal carcinoma SW620. Cancer cell lines were purchased from American Type Culture Collection (ATCC; Manassas, VA, USA). As control, nonneoplastic murine cardiofibroblasts were used. Cells were cultured in RPMI-1640 medium supplemented with $10 \%$ (v/v) fetal bovine serum (FBS), 1\% L-glutamine (v/v), 100 units/ml penicillin and $100 \mu \mathrm{g} / \mathrm{ml}$ streptomycin. The cells were grown at $37^{\circ} \mathrm{C}$ in a humidified atmosphere with $5 \% \mathrm{CO}_{2}$.

MTT assay. 5,7-dimethoxycoumarin activity on cell growth was estimated by MTT [3-(4,5-dimethylthiazol-2-yl)-2,5diphenyl tetrazolium bromide] assay, that is based on the cleavage of the yellow tetrazolium salt to purple formazan crystals by intracellular dehydrogenases (36). Briefly, 1-2x10 cells/well were seeded into sterile 96-well plates. After $24 \mathrm{~h}$, 5,7-dimethoxycoumarin was added to cell culture medium over a final concentration range of $0-500 \mu \mathrm{M}$ and the cells were incubated at $37^{\circ} \mathrm{C}$ in $5 \% \mathrm{CO}_{2}$ for a period of $24-72 \mathrm{~h}$. After the incubation period, MTT (Sigma-Aldrich) was added to each well and incubated for a further $4 \mathrm{~h}$. Then, medium was removed, blue crystals of MTT reduced by cells were dissolved with DMSO and cellular metabolism was determined by measuring the absorbance of samples at $570 \mathrm{~nm}$ in a microelisa reader. $\mathrm{IC}_{50}$ values were estimated following 72-h incubation.

Trypan blue exclusion test. B16 cells, cardiofibroblasts and A375 cells were seeded at a density of $1-2 \times 10^{4}$ cells/well in 24-well plates. After $24 \mathrm{~h}$ cells were treated with 100, 250 or $500 \mu \mathrm{M} 5$,7-dimethoxycoumarin and the plates were incubated at $37^{\circ} \mathrm{C}$ and $5 \% \mathrm{CO}_{2}$ for a period of $24-72 \mathrm{~h}$. After treatment, floating cells in the medium of each well were transferred to centrifuge tubes; adherent cells were washed, collected by trypsinization and mixed with the corresponding floating cells before centrifugation. Cells were stained with $0.4 \%$ trypan blue and counted in triplicate with an optic microscope with the aim to estimate the number of live and dead cells. Cell viability was expressed as a percentage of treated cells with respect to appropriate vehicle-treated controls, and toxicity as a percentage of dead cells with respect to the total number of cells. Moreover, B16 cells treated for $72 \mathrm{~h}$ were washed several times with medium to remove excess 5,7dimethoxycoumarin, counted and replaced in fresh medium at $1 \times 10^{4}$ cells/well without the compound. After 48-, 72- and $96-\mathrm{h}$ incubation at $37^{\circ} \mathrm{C}$ in $5 \% \mathrm{CO}_{2}$, the irreversible or reversible growth inhibitory effect of the compound was observed by trypan blue test.

The B16 and A375 treated cells were observed with an inverted microscope and photographed at $\mathrm{x} 10$ and $\mathrm{x} 20$ with a Nikon Coolpix 995 digital camera to detect any drug-induced morphological changes.

Cell cycle analysis. B16 and A375 cells were seeded and treated as described above. After 24-, 48- and 72-h incubation at $37^{\circ} \mathrm{C}$ in $5 \% \mathrm{CO}_{2}$, cells were washed, harvested, pelleted and stained with propidium iodide (PI) staining solution containing $50 \mu \mathrm{g} / \mathrm{ml} \mathrm{PI,} 0.5 \%$ RNase A and $0.1 \%$ Triton X100. After incubation for $30 \mathrm{~min}$ at $4^{\circ} \mathrm{C}$ in the dark, cell cycle distributions were analyzed by flow cytometry on a FACScalibur (Becton Dickinson, Mountain View, CA). Using Cellquest Pro software, the percentage of cells at different phases of the cell cycle was determined. PI was excited at $488 \mathrm{~nm}$, and fluorescence analyzed at $620 \mathrm{~nm}$. A total of 10,000 events in each sample were acquired.

Protoporphyrine IX (PpIX) analysis and phenotypic characterization with flow cytometry. B16, A375 and SW620 were seeded at a density of $1-1.5 \times 10^{4}$ cells $/ \mathrm{ml}$ in $24-w e l l$ plates. After $24 \mathrm{~h}$ cells were treated with methanol or 100 , 250 and $500 \mu \mathrm{M} 5,7$-dimethoxycoumarin. After 24-, 48- and 72-h incubation at $37^{\circ} \mathrm{C}$ in $5 \% \mathrm{CO}_{2}$, cells were washed with PBS, harvested by trypsinization, pelleted and resuspended in PFA $1 \%$. After at least 30 -min incubation at $4^{\circ} \mathrm{C}$, the samples were analyzed on a FACScalibur flow cytometer using the $488 \mathrm{~nm}$ line from an argon laser (Becton Dickinson, Mountain View, CA). In all, 10,000 cells, for each sample, were measured: scattering properties and fluorescence emitted from the cells at $670 \mathrm{~nm}$ were collected and analysed.

Melanin synthesis in B16 cells. B16 cells were seeded and treated as reported above, in order to measure extracellular and intracellular melanin according to the method of Hill et al (37). After 72 -h incubation at $37^{\circ} \mathrm{C}$ in $5 \% \mathrm{CO}_{2}$, the culture medium was removed, centrifuged (700 x g, $10 \mathrm{~min}$ ) and the supernatant was collected for extracellular melanin quantification; $1 \mathrm{ml}$ of 0.4 M HEPES buffer ( $\mathrm{pH}$ 6.8) and EtOH $(9: 1, \mathrm{v} / \mathrm{v})$ was added to $1 \mathrm{ml}$ of the medium and the OD at $475 \mathrm{~nm}$ was measured to quantify extracellular melanin by using a calibration curve obtained with synthetic melanin solutions. Cells were collected by trypsinization, pelleted, washed twice with PBS and digested in $1 \mathrm{ml} 1 \mathrm{~N} \mathrm{NaOH}$ for $16 \mathrm{~h}$ at room temperature; intracellular melanin was measured as described above. The stimulation of melanogenesis following the treatment was estimated as percentage of total melanin $(\mu \mathrm{g} / \mathrm{ml})$, calculated by the addition of intracellular and extracellular melanin, synthesized in treated cells with respect to vehicle-treated controls.

Western blot analyses. B16 cells were seeded and treated as described above. After a 72-h treatment time, cells were washed, collected by trypsinization and suspended in RIPA lysis buffer [1\% Nonidet P-40, 1\% sodium deoxycholate, $0.1 \% \mathrm{SDS}, 0.15 \mathrm{NaCl}, 0.01 \mathrm{M}$ sodium phosphate, $(\mathrm{pH} 7.2)$, $2 \mathrm{mM}$ EDTA, $50 \mathrm{mM}$ sodium fluoride, $0.2 \mathrm{mM}$ sodium vanadate and 100 units $/ \mathrm{ml}$ aprotinin]. After $1 \mathrm{~h}$ on ice, the 
A

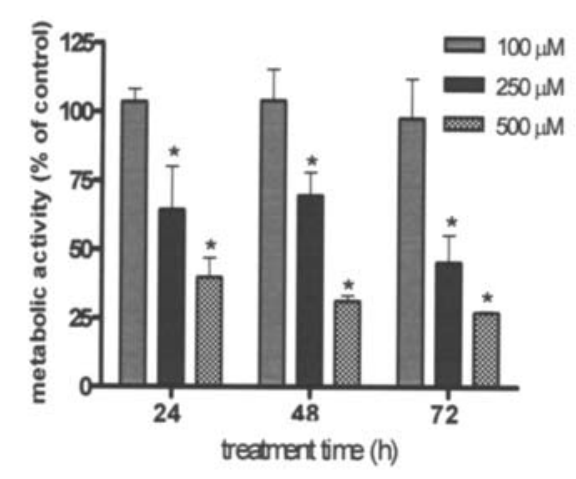

C

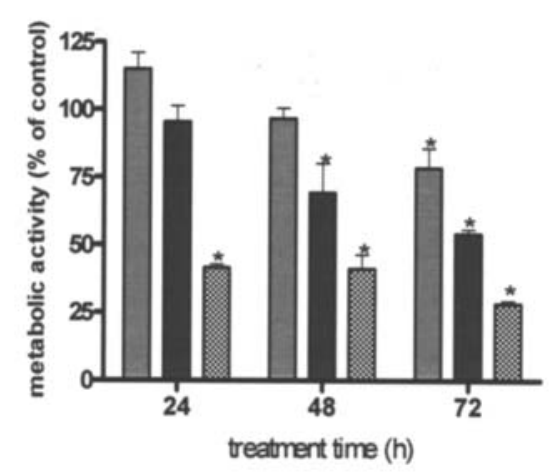

$\mathbf{E}$

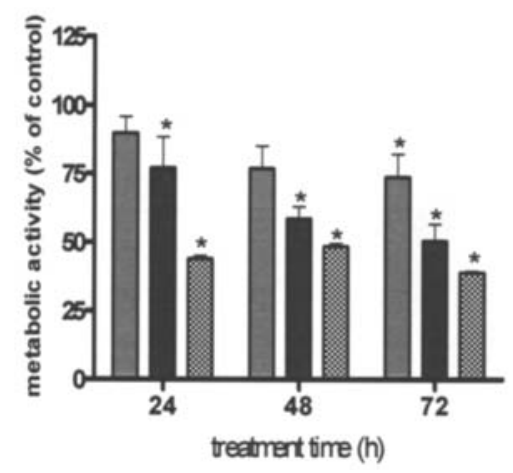

B

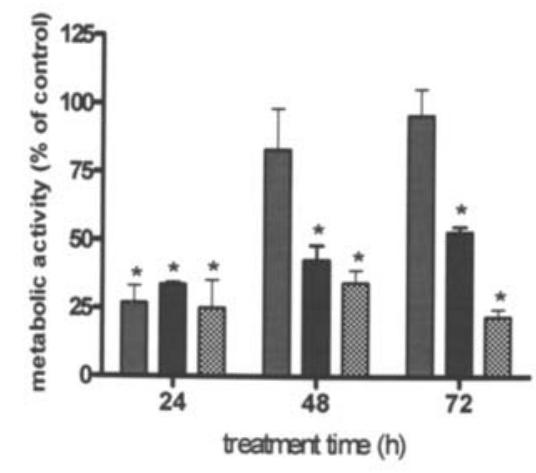

D

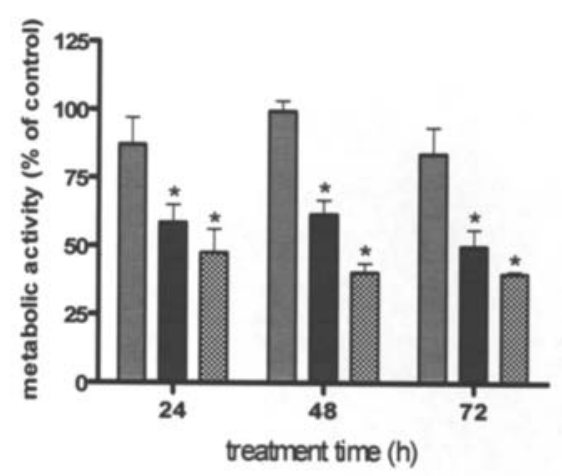

Figure 1. The effect of 5,7-dimethoxycoumarin on the metabolic activity of A375 (A), B16 (B), PC3 (C), SW620 (D), and MCF7 (E) cells following 24-, 48 and 72-h treatment. Cells were incubated with or without the compound using 100-, 250- and 500- $\mu \mathrm{M}$ doses and MTT assay was carried out as described in the Materials and methods. Results are the mean \pm SD from three separate experiments. ${ }^{*} \mathrm{P}<0.05$ versus vehicle control-treated cells.

cell lysates were cleared by centrifugation at $13000 \mathrm{x} \mathrm{g}$ for $15 \mathrm{~min}$ and the resultant supernatants collected and used for Bradford (38) assay to estimate protein concentration. Then, $100 \mu \mathrm{g}$ of total protein lysates were resolved on $12 \%$ sodium dodecyl sulphate polyacrylamide gels (SDS-PAGE) and the separated proteins were transferred to PVDF membrane. The level of MAPK expression in each sample was detected using mouse monoclonal primary antibody against phospho-ERK 1/2 (Tyr-204), diluted 1:250 in TTBS solution containing 1\% $(\mathrm{w} / \mathrm{v})$ of BSA, followed by peroxidase-conjugated goat antimouse secondary antibody and enhanced chemiluminescence visualization. Membranes were stripped and reprobed with $\alpha$-tubulin primary antibody as a protein loading control. The antibodies and detection system were purchased from Santa Cruz Biotechnology, Inc. (Santa Cruz, CA).
Statistical analysis. Student's t-test was employed to determine the significance of any reduction in cellular viability, the increase of melanin synthesis and any alteration in cell cycle following the treatment. A probability of $\leq 0.05$ was deemed statistically significant.

\section{Results}

5,7-dimethoxycoumarin reduces the metabolic activity of murine and human cell lines. In the first set of experiments, the anti-neoplastic activity of 5,7-dimethoxycoumarin in both murine and human cell lines of melanoma was measured using MTT assay in basic culture conditions for each cell line, to evaluate any level of cell growth. As control, we also evaluated the effect of the compound in various human adenocarcinoma 
Table I. $\mathrm{IC}_{50}$ of 5,7-dimethoxycoumarin in different cell lines following 72-h treatment. ${ }^{\mathrm{a}}$

\begin{tabular}{lccc}
\hline Histological type & Cell line & $\mathrm{IC}_{50}(\mu \mathrm{M})^{\mathrm{b}}$ & $\mathrm{IC}_{50}(\mu \mathrm{M})^{\mathrm{c}}$ \\
\hline Human melanoma & $\mathrm{A} 375$ & 300 & 142 \\
Murine melanoma & B16 & 260 & 109 \\
Human adenocarcinoma & MCF7 & 250 & - \\
& PC3 & 285 & - \\
& SW620 & 325 & - \\
\hline
\end{tabular}

${ }^{a}$ Cells were incubated with or without the compound using 100-, 250- and 500- $\mu \mathrm{M}$ doses; then, MTT assay and trypan blue exclusion test were carried out, as described in the Materials and methods. A graph of viability versus drug concentration was used to calculate $\mathrm{IC}_{50}$ values for each cell line. ${ }^{\mathrm{b}} \mathrm{IC}_{50}$ values as obtained by MTT assay. ${ }^{~}{ } C_{50}$ values as obtained by trypan blue exclusion test.

cell lines. The compound significantly reduced metabolic activity, in a dose-dependent manner up to $70 \%$ after $72-\mathrm{h}$ treatment with respect to the control. The concentration of $100 \mu \mathrm{M}$ did not show a significant growth inhibition activity, except for B16, PC3 and MCF7 lines. The concentrations of 250 and $500 \mu \mathrm{M}$ significantly inhibited cellular proliferation in each incubation time for every cell line (Fig. 1). In Table I, $\mathrm{IC}_{50}$ values, estimated after $72 \mathrm{~h}$ of treatment, are reported and evidence that 5,7-dimethoxycoumarin exhibited a clear effect not only in melanoma but also in adenocarcinoma cell lines.

Effect of 5,7-dimethoxycoumarin on the growth and death of melanoma cell lines. MTT assay did not reveal if the reduction of proliferation was related to growth arrest or cell death since both mechanisms could result in reduced cell numbers and an apparent loss of viability. To establish that, a trypan blue exclusion test was carried out on melanoma cell lines. The results reported in Fig. 2A show that 5,7-dimethoxycoumarin possessed an antiproliferative activity on B16 cell growth at all the concentrations tested. The compound inhibited the growth of B16 cells significantly, as compared with the control group, at 48 and $72 \mathrm{~h}$, accounting for $35-47 \%, 48-68 \%$ and $61-72 \%$ inhibition, at the doses of 100,250 and $500 \mu \mathrm{M}$, respectively. The inhibitory effect was time- and dose-dependent.

In the same way, the treatment with 5,7-dimethoxycoumarin significantly reduced the proliferation of A375 cells (Fig. 2B), accounting for $0-45 \%, 17-68 \%$ and $41-80 \%$ of reduction at the doses of 100,250 and $500 \mu \mathrm{M}$, respectively. The inhibition of cell growth was significant with respect to the control in each treatment time, except for the concentration of $100 \mu \mathrm{M}$ at $24 \mathrm{~h}$. The inhibitory effect was time- and dose-dependent.

$\mathrm{IC}_{50}$ values at $72 \mathrm{~h}$ were obtained also through trypan blue test and they accounted for 109 and $142 \mu \mathrm{M}$ in B16 and A375, respectively (Table I). Interestingly, they were lower than those derived from MTT assay at the same time of treatment. That probably is a consequence of the lower reliability of an indirect assay, such as MTT assay, compared to a direct one such as the trypan blue test (39).

Moreover, the effect of the compound on murine melanoma cells was long lasting, since the same cells previously treated
A

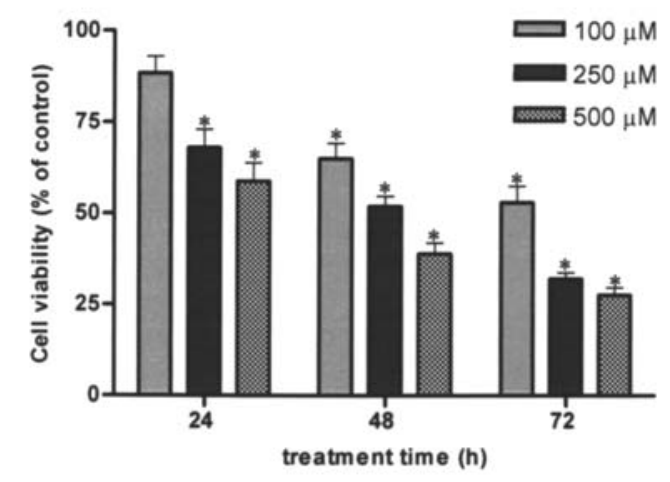

B

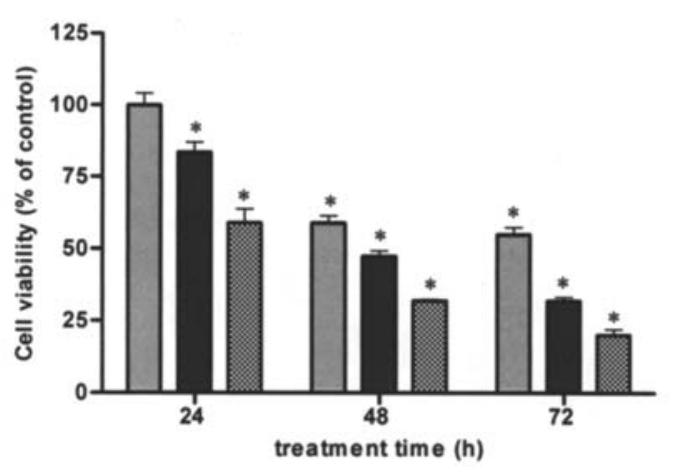

C

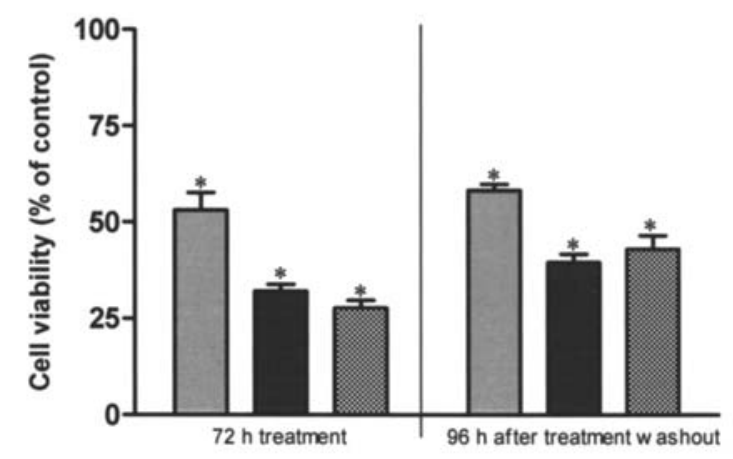

Figure 2. The effect of 5,7-dimethoxycoumarin on murine and human melanoma cell lines. (A) B16 and (B) A375 cell viability following 24-, 48and 72-h treatment. Cells were incubated with or without the compound using 100-, 250- and 500- $\mu \mathrm{M}$ doses and the trypan blue exclusion test was carried out. (C) The irreversible effect of 5,7-dimethoxycoumarin on B16 cell growth. Cells were incubated with or without the compound using 100-, 250- and 500- $\mu \mathrm{M}$ doses for $72 \mathrm{~h}$; then, they were reseeded without treatment for $96 \mathrm{~h}$. Data are expressed as \% of cell viability with respect to vehicle control as described in the Materials and methods. Results are the mean \pm SD from three separate experiments. ${ }^{*}<<0.05$ versus vehicle control-treated cells.

at doses of 100,250 , and $500 \mu \mathrm{M}$, washed, reseeded and cultured without treatment, showed a significant reduced performance of proliferation with respect to untreated cells. After $96 \mathrm{~h}$ of incubation at $37^{\circ} \mathrm{C}$ in $5 \% \mathrm{CO}_{2}$, the growth reduction produced by previous treatment was $42 \%, 61 \%$ and $57 \%$ at the doses of 100,250 and $500 \mu \mathrm{M}$, respectively. Statistical differences were observed between the values obtained with 100 and $250 \mu \mathrm{M}$ doses, and with 100 and $500 \mu \mathrm{M}$ doses (Fig. 2C). These results evidenced that the antiproliferative effect of the compound was irreversible since 
A

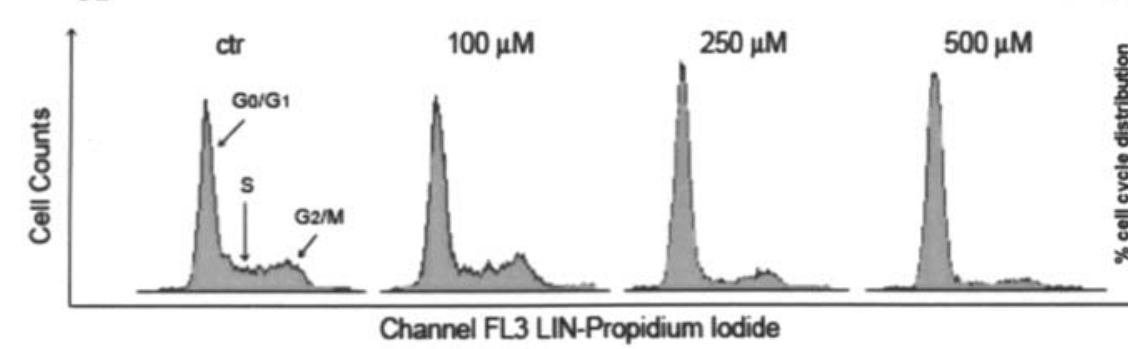

B

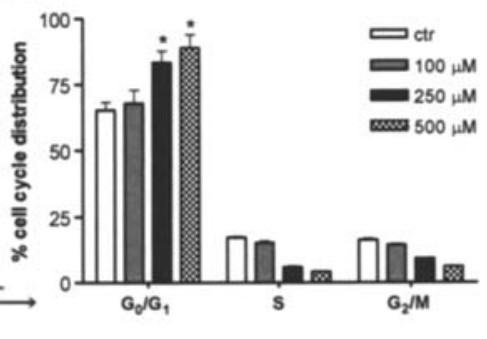

Figure 3. Effect of 5,7-dimethoxycoumarin on cell cycle progression in B16 cells after 24-h treatment. Cells were incubated with or without the compound using 100-, 250- and 500- $\mu \mathrm{M}$ doses. After treatment, cells were stained with propidium iodide and flow cytometric analysis was performed as described in the Materials and methods. (A) Fluorescence from propidium iodide. (B) The percentage of cell cycle distribution data for each treatment group. Results are the mean $\pm \mathrm{SD}$ from three separate experiments. ${ }^{*} \mathrm{P}<0.05$ versus vehicle control-treated cells. Ctr, control.
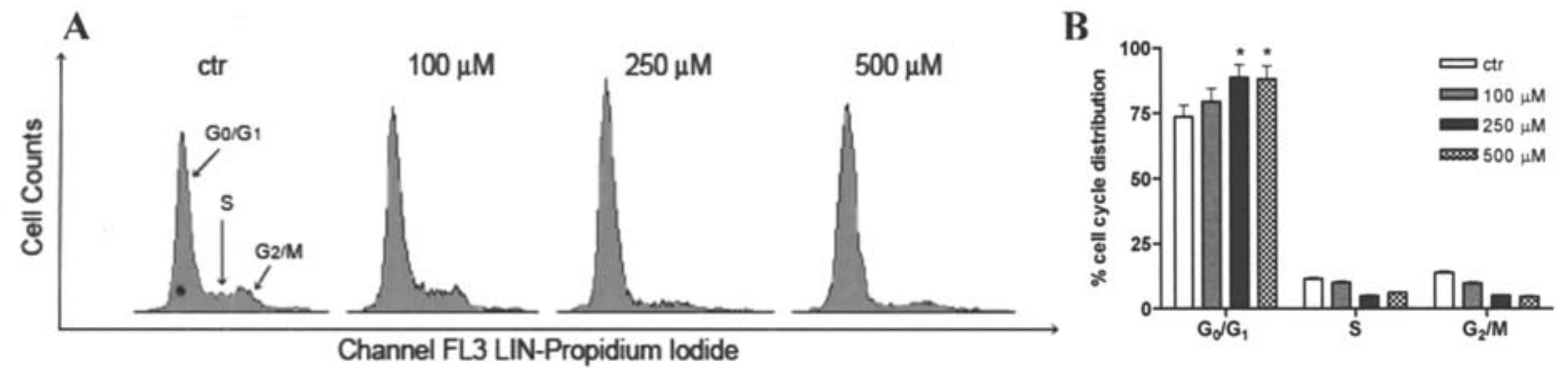

Figure 4. Effect of 5,7-dimethoxycoumarin on cell cycle progression in A375 cells after 48-h treatment. Cells were incubated with or without the compound using 100-, 250- and 500- $\mu \mathrm{M}$ doses. After treatment, cells were stained with propidium iodide and flow cytometric analysis was performed as described in the Materials and methods. (A) Fluorescence from propidium iodide. (B) The percentage of cell cycle distribution data for each treatment group. Results are the mean \pm SD from three separate experiments. ${ }^{*} \mathrm{P}<0.05$ versus vehicle control-treated cells. Ctr, control.

proliferation did not return to control levels even at the end of the 96-h recovery period.

The percentage of dead cells calculated as explained in the Materials and methods sections, after treatments for both cell lines was also evaluated. No significant cytotoxicity was observed at any experimental time and dose with respect to the control (data not shown).

The 5,7-dimethoxycoumarin did not change significantly the growth of non-neoplastic cardiofibroblasts for any of the used concentrations (data not shown).

5,7-Dimethoxycoumarin blocks the cycle of melanoma cells in the $G_{0} / G_{I}$ phase. Since the strong inhibitory effect induced by 5,7-dimethoxycoumarin could be related with a decrease of DNA synthesis, we then investigated its effect on cell cycle events. After treatment, we demonstrated by FACS analysis, that 5,7-dimethoxycoumarin induced a strong and dose-dependent arrest of cell cycle progression in the $G_{0} / G_{1}$ phase in B16 and A375 cell lines, when compared with the control sample, with reduction of $S$ and $\mathrm{G}_{2} / \mathrm{M}$ phase population. In regard to B16 cells (Fig. 3), the accumulation in the $G_{0} / G_{1}$ after 24-h phase was significant at high dose and consistent with growth arrest when compared to the control.

An accumulation of melanoma cells in the $\mathrm{G}_{0} / \mathrm{G}_{1}$ phase was detected also after 48- and 72-h treatment, although the differences with respect to the control were less significant than after $24 \mathrm{~h}$ of incubation (data not shown). Moreover, after $72 \mathrm{~h}$ of treatment the dose of $500 \mu \mathrm{M}$ induced an accumulation of B16 cells in the sub- $\mathrm{G}_{1}$ phase of $\sim 10 \%$ (data not shown). Similarly, in A375 cells, a $G_{0} / G_{1}$ arrest was observed at the $500-\mu \mathrm{M}$ dose after $24 \mathrm{~h}$ (data not shown), which did not change at later treatment times. However, $250-\mu \mathrm{M}$ dose of 5,7-dimethoxycoumarin showed a significant increase after 48-h treatment (Fig. 4).

Morphological effects of 5,7-dimethoxycoumarin in melanoma cells. Since the treatment with 5,7-dimethoxycoumarin showed low cytotoxicity, we hypothesised that growth inhibition was due to the induction of a differentiation process that is generally coupled to a block in cellular proliferation $(40,41)$. To verify this hypothesis first we evaluated the morphology of melanoma cell lines after treatment under an inverted microscope. B16 cell analysis by digital images (Fig. 5) showed a dose-dependent decrease of cellular density in the culture treated with different doses of 5,7-dimethoxycoumarin, according to the results obtained with the trypan blue test. Moreover, a clear morphological change was detected in cells, since the treatment induced the formation of dendritelike projections which gave a star-like shape to the cells compared to rounded untreated cells. This effect was more evident with the increase of treatment time and concentration and after 5,7-dimethoxycoumarin washout it did not recover the control morphology (data not shown). Similar results were obtained for A375 cells regarding cellular density, but generally morphological changes were less evident than those obtained in B16 cells (data not shown). 

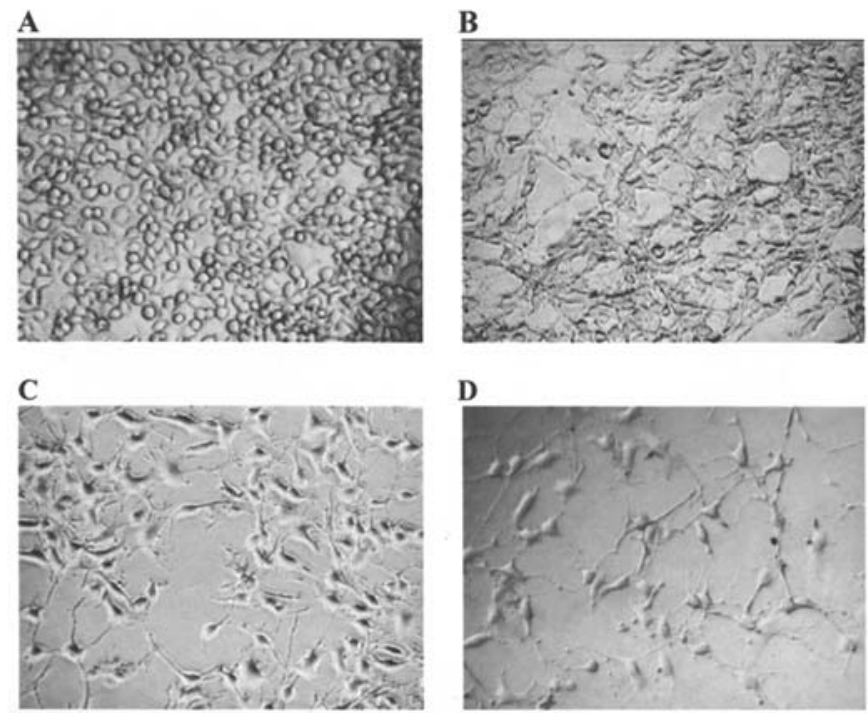

Figure 5. Effect of 100- (B), 250- (C) and 500- $\mu \mathrm{M}$ (D) 5,7-dimethoxycoumarin with respect to control (A) on B16 cell growth and morphology after 72-h incubation. Cells were seeded and treated as described in the Materials and methods; then digital images were obtained by observation with an inverted microscope at $\mathrm{x} 10$.

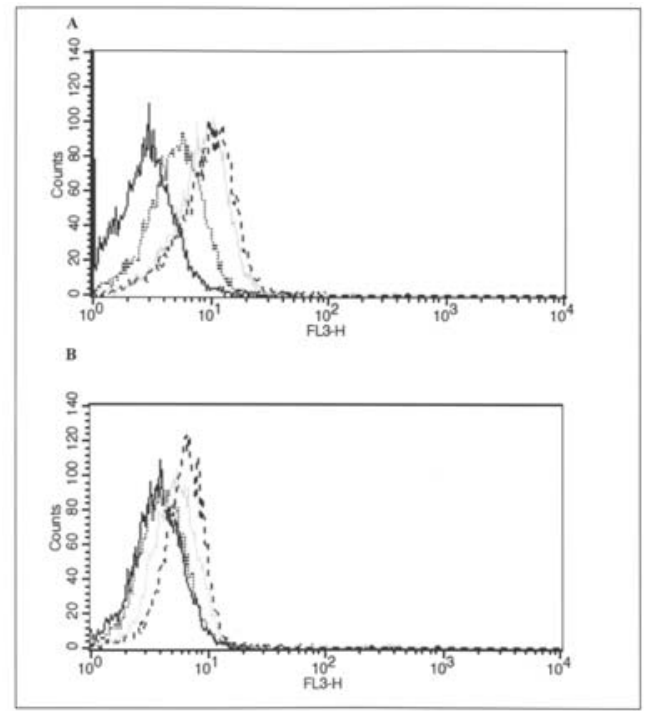

Figure 6. PpIX production in B16 (A) and A375 (B) cells treated with solvent (solid black line) or with 100- (dotted line), 250- (gray line) and $500-\mu \mathrm{M}$ (dashed line) 5,7-dimethoxycoumarin for $72 \mathrm{~h}$. The data shown are representative of 4 independent experiments.

5,7-Dimethoxycoumarin increased PpIX accumulation and altered phenotypic characteristics in melanoma cells. Cellular differentiation has been related to an increase of intracellular PpIX accumulation for some cancer cell lines including B16 cells $(42,43)$. To investigate if the treatment with 5,7dimethoxycoumarin induced a significant augmentation in PpIX production, melanoma cell lines were treated with doses of 100, 250 and $500 \mu \mathrm{M}$ for $72 \mathrm{~h}$. As shown in Fig. 6, PpIX accumulation was enhanced following an increase of the dose of tested compound for both B16 (Fig. 6A) and A375 (Fig. 6B) cell lines. After 72-h incubation at the higher concentration of 5,7-dimethoxycoumarin used, the increase
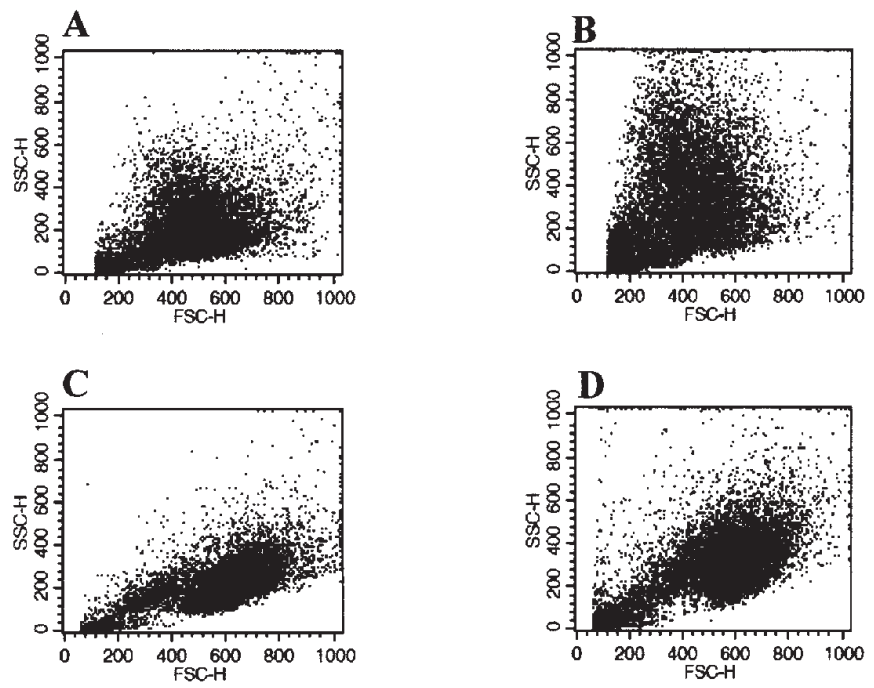

Figure 7. Light scatter of B16 (A and B) and A375 cells (C and D) incubated or not with $500-\mu \mathrm{M}$ 5,7-dimethoxycoumarin for $72 \mathrm{~h}$. In the scattergrams 5,7-dimethoxycoumarin-treated cancer cells (B-D) exhibited less forward scatter and much more side scatter than solvent-treated cells (A-C).

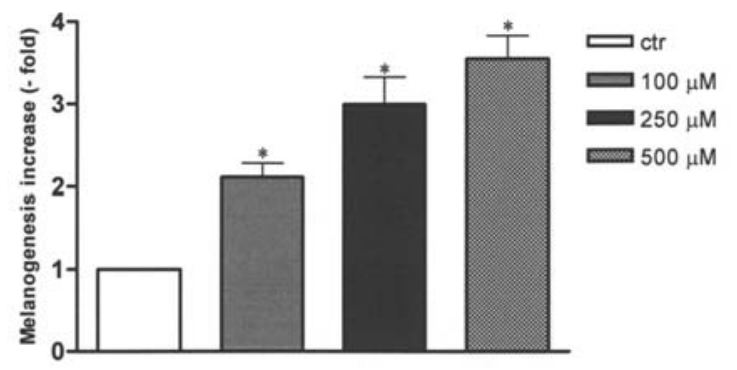

Figure 8. The effect of 5,7-dimethoxycoumarin on melanin synthesis in B16 cells following treatment for $72 \mathrm{~h}$ in vitro. Cells were incubated with or without the compound using 100-, 250- and 500- $\mu \mathrm{M}$ doses. The melanin concentrations $(\mu \mathrm{g} / \mathrm{ml})$ and the increase in melanin production were estimated as described in the Materials and methods. Results are the mean \pm SD from three separate experiments. ${ }^{*} \mathrm{P}<0.05$ versus vehicle control-treated cells.

of PpIX was 3.3-fold (B16) and 1.6-fold (A375) with respect to the control. Instead, in SW620 cells, used as control, accumulation of PpIX was unchanged after treatment in the same experimental conditions (data not shown).

Further phenotypic alterations were observed through cytofluorometric analysis of both treated melanoma cell lines. A change in light scatter properties of B16 and A375 cells treated with 5,7-dimethoxycoumarin was detected. In particular, a decrease of FSC (forward scatter) mean values with respect to the solvent control was observed; at the same time, SSC (side scatter) mean values increased strongly following the treatment. This effect was more pronounced in B16 than A375 cells. In Fig. 7 results relative to the treatment with a $500-\mu \mathrm{M}$ dose for $72 \mathrm{~h}$ are shown. These effects were timeand dose-dependent (data not shown). Also phenotypic characterization of SW620 cells was carried out, but changes in FSC and SSC were not detected after treatment, using the same experimental conditions (data not shown).

The melanogenesis process was induced in B16 cells following treatment with 5,7-dimethoxycoumarin. Since the changes in 


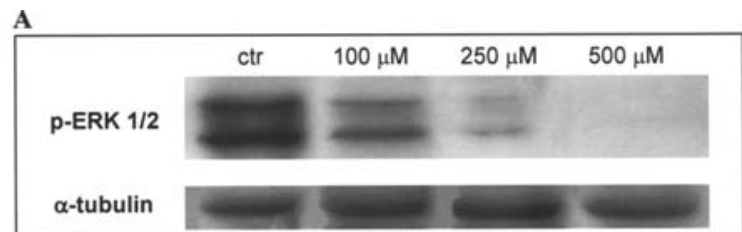

B

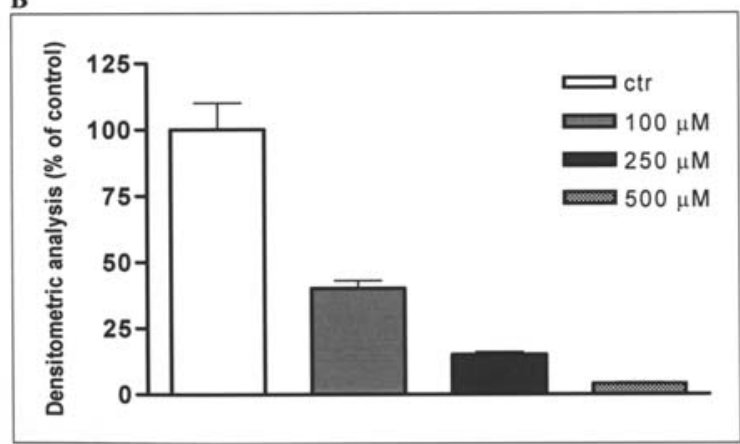

Figure 9. The effect of 5,7-dimethoxycoumarin on ERK 1/2 activity in B16 cells following treatment for $72 \mathrm{~h}$. Cells were incubated with or without the compound using 100-, 250- and 500- $\mu \mathrm{M}$ doses. (A) After treatment, total cell lysates were prepared and subjected to SDS-PAGE followed by Western immunoblotting as described in the Materials and methods. Activation level of ERK 1/2 was analysed with its corresponding phospho-specific antibody. (B) Densitometric data were expressed as percentage of p-ERK reduction with respect to the control. Data are the mean \pm SD from three separate experiments.

light scatter properties of B16 and A375 cells could be related to an increase of cellular complexity, we further investigated the melanogenesis process in B16 cells, where the changes in light scatter properties were more evident compared to the A375 cells. After 72-h incubation, 5,7-dimethoxycoumarin was demonstrated to induce melanin synthesis in B16 treated cells as shown in Fig. 8. Both the extracellular and intracellular melanin quantity significantly increased with respect to the control for all tested doses. Total melanin calculation revealed that the melanogenesis was significantly increased in a dose-dependent manner by approximately 2.12-, 3.0-, and 3.55-fold with respect to the control for 100, 250 and $500 \mu \mathrm{M}$ 5,7-dimethoxycoumarin, respectively. These results also demonstrated that 5,7-dimethoxycoumarin induced a differentiation program in B 16 cells since stimulation of melanogenesis is considered a well-known marker of differentiation for melanoma cells (44).

Effects of 5,7-dimethoxycoumarin on ERK 1/2 activation. To unravel the potential mechanism underlying 5,7-dimethoxycoumarin-induced effects, inhibition of cell growth and stimulation of the differentiation process, we examined the alterations in activation of a MAPK signalling pathway following treatment. The effects of 5,7-dimethoxycoumarin on ERK $1 / 2$ phosphorylation in the B16 cell line after 72-h treatment are shown in Fig. 9A. The treatment of B16 cells with 5,7-dimethoxycoumarin inhibited the activation of the protein in a dose-dependent manner resulting in a moderate to complete inhibition. Densitometric analysis allowed us to calculate the treatment effect, with respect to the methanol control, in phospho-ERK (p-ERK) expression: the reduction of p-ERK $1 / 2$ expression was $60 \%, 85 \%$ and $96 \%$ for 100 , 250 and $500 \mu \mathrm{M}$, respectively (Fig. 9B).

\section{Discussion}

Among the biological properties possessed by coumarins, one that makes these compounds attractive is the antitumour activity showed by some members of this chemical group. In particular, 5,7-dimethoxycoumarin, a coumarin derivative identified in a few vegetable species and recently also in Carica papaya (30), was the object of our investigation since it has been scarcely studied up to now. We decided to test the antitumour efficacy of this compound on different cancer cell lines in vitro by using first MTT assay, widely used for high through-put screening of new drugs. Our results indicated that 5,7-dimethoxycoumarin inhibited the growth of several cell lines, of melanoma and carcinoma origin, in a comparable manner; our data showed that the effect was not species- or line-specific. Since MTT is an indirect colourimetric assay, the trypan blue test was then used to directly assess the cell survival rate in melanoma lines following treatment. Antineoplastic activity of the molecule was confirmed, but $\mathrm{IC}_{50}$ values obtained after a $72-\mathrm{h}$ treatment were considerably lower than those from the MTT test. This discrepancy in test sensitivity could be explained considering that MTT assay is based on intracellular dehydrogenases whose activity could be alterated by the tested compound (45). Not shown results allowed us to exclude the feasibility of a direct MTT reduction by 5,7-dimethoxycoumarin. By direct cell counting it is possible to distinguish between cytostatic and cytotoxic effect; in this case, our results indicated a cytostatic activity exerted by this molecule, at least in the experimental conditions used. However, we can not rule out that higher doses and longer incubation times could exert cytotoxic activity, since our experimental observations were extended for up to $72 \mathrm{~h}$ of culture and at a maximum dosage of $500 \mu \mathrm{M}$ in the presence of 5,7-dimethoxycoumarin.

FACS analysis demonstrated that 5,7-dimethoxycoumarin caused an arrest of the cell cycle in the $G_{0} / G_{1}$ phase with a decrease of cell population in synthesis and mitosis phases in melanoma cells. Other coumarins with anticancer properties blocked the cell cycle either in the $G_{0} / G_{1}$ phase (18) or in the $\mathrm{S}$ phase (22). Since most of the antineoplastic drugs in clinical use block the cell cycle in the $S$ or $G_{2} / M$ phases whereas 5,7-dimethoxycoumarin blocks the cell cycle in the $\mathrm{G}_{1}$ phase, a combination of 5,7-dimethoxycoumarin with currently used drugs might possibly improve therapies of melanoma. Moreover, cytostatic activity proved irreversible by culturing the B16 cells, previously treated, without the compound; after some days of culture in fresh medium the treated cells did not recover control growth. Generally, an irreversible growth inhibition is determined by either apoptotic cell death or differentiation process (46). In B16 cells following treatment with 5,7-dimethoxycoumarin, we observed significant morphological changes and characteristic markers specific of melanoma cell differentiation. In fact, following incubation, B16 cells gained a star-like shape with dendritic projections. Morphological alterations were also revealed through flow cytometry analysis. Treated melanoma cells exhibited subtle reduction of FSC compared to the control, indicating that the incident light was absorbed rather than transmitted through the cells presumably due to an augmentation of light absorbing melanin. However, we can not rule out the possibility that 
such changes could be due to cell size reduction or to the presence of other cellular components that absorb incident light. On the contrary, we observed a high increase of SSC that generally indicates the granularity of a cell, in melanoma treated cells, especially in the B16 cell line, after treatment with 5,7-dimethoxycoumarin. We hypothesised that this reflects an increase of intracellular number of melanosomes, supported by the evidence that SW620, a human adenocarcinoma cell line, did not change light scatter properties after treatment with the compound.

Based on these data, we investigated the melanin content in B16 cells, where the effect of the 5,7-dimethoxycoumarin on light scatter properties was more evident. An augmentation in melanin synthesis was observed in treated cells, as hypothesised above. Morphological changes with dendrite outgrowth and melanogenesis are considered specific markers of differentiation for B16 cells (40).

It is well known that some melanoma differentiation agents, such as UV-B (47) and cyclic adenosine monophosphate (cAMP) (48), stimulate dendricity and melanogenesis after blocking cells in the $\mathrm{G}_{0} / \mathrm{G}_{1}$ phase as well as our tested compound.

We suggested that 5,7-dimethoxycoumarin induced a terminal differentiation in B16 cells that eventually causes cell death, even if the ultimate fate of the growth arrested cells was not analysed. This hypothesis is supported by the observation that exposure to the highest dose of compound for $72 \mathrm{~h}$ led to a small accumulation of cells in the sub- $\mathrm{G}_{1}$ phase; moreover, the compound irreversibly induced both cell growth inhibition and morphological changes. A less significant change in cellular shape was observed also in the treated A375 cell line. It has been reported that novobiocin, a coumarin derivative with antibiotic properties, inhibited B16 cell proliferation, but not in a reversible manner, and induced cellular differentiation (49). Recently, novel synthetic nitrated coumarins, namely 6-nitro-7-hydroxy-coumarin and 3,6,8trinitro-7-hydroxycoumarin have been shown to be antiproliferative and differentiation agents in human melanoma cells (50).

As a further marker of differentiation we monitored the production of PpIX, a photosensitiser compound synthesized and localized in the mithocondria as intermediate molecules in the heme biosynthesis pathway, of which 5-aminolevulinic acid (ALA) is the first intermediate. The treated melanoma cells emitted a PpIX fluorescence higher than untreated cells owing to a synthesis increase and intracellular accumulation of PpIX during treatment (51). It has been reported that the induction of differentiation enhanced PpIX accumulation in some cell lines, such as prostate cancer cells (51), fibroblasts, B16 cells (42) and keratinocytes (52). However, the relationship between tumour cell differentiation and photosensitizer accumulation is poorly defined (53) since some differentiation agents, such as butyrate, did not enhance PpIX accumulation whereas others, such as hexamethylene bisacetamide (HMBA) and methotrexate, did $(43,54)$. To the best of our knowledge, this is the first evidence that a member of the coumarin group enhanced PpIX accumulation at least in melanoma cells; this observation was not reproduced in SW620 cells suggesting a cell-type specific effect. PpIX production is exploited clinically in photodynamic therapy of cancer (PDT), accepted in the care of superficial epithelial neoplasias. This therapy uses ALA, an inert pharmacological precursor that remains inactive until it is converted into a photosensitising agent (PpIX) that is activated by light to generate reactive oxygen species (ROS), leading to cancer cell death via necrosis or apoptosis (55). A combination therapy using a differentiation agent that specifically enhances PpIX production in cancer cells and PpIX precursor could be very useful, because tumour eradication with ALA-PDT is not always obtained. Based on this premise, our data are particularly interesting, although more studies are needed to establish the interaction between 5,7-dimethoxycoumarin and ALA-PDT.

With the aim to elucidate the mechanism by which 5,7-dimethoxycoumarin reduced proliferation and induced differentiation in treated B16 cells, we focused our attention on the phosphorylation status of ERK $1 / 2$ following treatment. ERK 1/2 (extracellular signal-regulated kinase) is a member of the Ras/Raf/Mek/ERK mitogen-activated protein kinase (MAPK) signalling pathway that regulates cell survival, proliferation and differentiation processes following transmission of a wide variety of extracellular stimuli from the cell surface to the nucleus (56). Its phosphorylation by MEK 1/2 in serine and threonine residues activates a series of transcription factors in the nucleus, such as c-Myc, NF-IL6 and Elk-1, initiating the transcription of genes encoding for proteins that promote cell cycle progression through $\mathrm{G}_{0} / \mathrm{G}_{1}$ phase and from $\mathrm{G}_{0} / \mathrm{G}_{1}$ to $\mathrm{S}$ phase, such as the cyclins $\mathrm{D}$ and $\mathrm{E}$, and then cell proliferation $(56,57)$. Using Western blot analysis, we detected a reduction in the phosphorylation of ERK 1/2, following incubation of B16 cells with 5,7-dimethoxycoumarin; the inhibition of the MAPK activation was more evident with an increase of tested compound concentration and this data was comparable with cell cycle analysis and trypan blue assay results, since reduction of ERK phosphorylation by the treatment caused the block in the $\mathrm{G}_{0} / \mathrm{G}_{1}$ phase and subsequently growth reduction and differentiation. It has been reported that Ras/Raf/MEK/ERK pathway is constitutively activated, following mutation in the catalytic domain of these protein kinases, in a high percentage of human melanoma cells; particularly, an activating mutation of B-Raf that induces a constitutive phosphorylation of ERK has been detected in $66 \%$ of human melanomas (58). It is known that the treatment of melanoma cells with either U0126 (MEK 1 inhibitor) or PD098059 (MEK 2 inhibitor) causes an inhibition of cell growth and a reduction in levels of matrix metalloproteinases MMP-1 and MMP-2, involved in tumor cell invasion, demonstrating that activation of ERK is an important event in melanoma development (58). Based on this assumption, the MAPKs of Ras/Raf/MEK/ERK signalling pathway are considered key molecular targets of novel therapy in melanoma cancer research and several agents that target this pathway are already undergoing clinical testing (59). Therefore, we should further investigate if 5,7-dimethoxycoumarin reduces ERK $1 / 2$ activation by inhibition of catalytic activity of upstream kinases to define the therapeutic potential of the compound.

The microphthalmia-associated transcription factor (Mitf) is another substrate regulated by p-ERK $1 / 2$ and it is involved in differentiation, proliferation and survival of melanocytes $(60,61)$. It activates the transcription of the gene encoding for tyrosinase, which catalyses the hydroxylation of L-tyrosine 
to L-3,4-dihydroxyphenylalanine (L-DOPA) followed by the oxidation of L-DOPA to dopaquinone, two key steps in the pathway of melanin synthesis (62). It is known that the MAPKs play a key role in tyrosinase expression and the melanogenesis process; particularly, p-ERK 1/2 downregulates Mitf by phosphorylation at serine 73 and subsequent degradation. Furthermore, Englaro et al (63) observed that inhibition of Ras/Raf/MEK/ERK MAPK pathway led to the B16 cell differentiation and melanogenesis increasing tyrosinase expression and activity. During melanogenesis induced by some agents, including $\alpha$-melanocyte stimulating hormone $(\alpha-\mathrm{MSH})$ and forskolin, the Mitf transcriptional activity is regulated through the cAMP-mediated pathway with the activation of protein kinase A (PKA) that upregulates the Mitf gene transcription by phosphorylation of the transcriptional factor CREB (cAMP-response element-binding protein) (64). Also PpIX induces melanogenesis through the cAMP-mediated pathway activating the soluble guanylate cyclase and elevating intracellular cGMP (cyclic guanine monophosphate) content (65), which was demonstrated to increase cAMP content by inhibition of cAMP phosphodiesterase (66). In our study, during melanogenesis induced by 5,7-dimethoxycoumarin in B16 cells, we observed a dephosphorylation of MAPK ERK $1 / 2$, in agreement with previous studies, and an intracellular accumulation of PpIX. Therefore, induction of melanogenesis in treated B16 cells could be regulated through both Ras/Raf/ MEK/ERK MAP kinase and cAMP-mediated pathways.

This study showed the in vitro anticancer activity of 5,7dimethoxycoumarin in melanoma cells through cell cycle arrest and differentiation induction. Furthermore, cell growth of non-neoplastic cardiofibroblasts was not modified significantly by the treatment suggesting a selective antiproliferative effect of the compound in cancer cell lines. These findings should be developed with in vivo studies in preclinical animal models. The antigrowth effect of the compound on human cancer cell lines used in the study should be further investigated. Finally, it will be interesting to determine the molecular target in the Ras/Raf/MEK/ERK MAP kinase of 5,7-dimethoxycoumarin and the mechanism involved in the melanogenesis process induced by the compound.

\section{Acknowledgements}

We are grateful to Dr Di Nardo for murine cardiofibroblasts.

\section{References}

1. Egan D, O'Kennedy R, Moran E, Cox D, Prosser E and Thornes RD: The pharmacology, metabolism, analysis, and applications of coumarin and coumarin-related compounds. Drug Metab Rev 22: 503-529, 1990.

2. Cox D, O'Kennedy R and Thornes RD: The rarity of liver toxicity in patients treated with coumarin (1,2-benzopyrone). Hum Exp Toxicol 8: 501-506, 1989.

3. Laurin P, Klich M, Dupis-Hamelin C, Mauvais P, Lassaigne P, Bonnefory A and Musicki B: Synthesis and in vitro evaluation of novel highly potent coumarin inhibitors of gyrase B. Bioorg Med Chem Lett 9: 2079-2084, 1999.

4. Suttie JW: The biochemical basis of warfarin therapy. Adv Exp Med Biol 214: 3-16, 1987.

5. Roma G, Braccio MD, Carrieri A, Grossi G, Leoncini G, Signorello MG and Carotti A: Coumarin, chromone, and 4(3H)pyrimidinone novel bicyclic and tricyclic derivatives as antiplatelet agents: synthesis, biological evaluation, and comparative molecular field analysis. Bioorg Med Chem 11: 123-138, 2003.
6. Hoult RJS and Paya M: Pharmacological and biochemical action of simple coumarins: natural products with therapeutic potential. Gen Pharmacol 27: 713-722, 1996.

7. Campos-Toimil M, Orallo F, Santana L and Uriarte E: Synthesis and vasorelaxant activity of new coumarin and furocoumarin derivatives. Bioorg Med Chem Lett 12: 783-786, 2002.

8. Fang Y, Li Z and Watanabe Y: Pharmacokinetics of a novel anti-asthmatic, scoparone, in the rabbit serum assessed by a simple HPLC method. J Ethnopharmacol 86: 127-130, 2003.

9. Pillai SP, Menon SR, Mitscher LA, Pillai CA and Shankel DA: Umbelliferone analogues and their potential to inhibit benzo(a)pyrene and hydrogen peroxide induced mutations. J Nat Products 62: 1358-1362, 1999.

10. Paya M, Halliwel B and Hoult JR: Interactions of a series of coumarins with reactive oxygen species: scavenging of superoxide, hypochlorous acid and hydroxyl radicals. Biochem Pharmacol 44: 205-214, 1992.

11. Maucher A, Kager M and von Angerer E: Evaluation of the antitumour activity of coumarin in prostrate cancer models. $\mathbf{J}$ Cancer Res Clin Oncol 119: 150-154, 1993.

12. Sharma S, Stutzman D, Kellof JG and Steele VE: Screening of potential chemopreventive agents using biochemical markers of carcinogenesis. Cancer Res 54: 5848-5855, 1994.

13. Egan D, James P, Cooke D and O'Kennedy R: Studies on the cytostatic and cytotoxic effects and mode of action of 8-nitro-7hydroxycoumarin. Cancer Lett 118: 201-211, 1997.

14. Hayes JD, Pulford DJ, Ellis EM, McLeod R, James RFL, Seidegard J, Mosialou E, Jernstrom B and Neal GE: Regulation of rat glutathione S-transferase A5 by cancer chemo-preventative agents: mechanisms of inducible resistance to aflatoxin B1. Chemicobiol Interact 111-112: 51-67, 1998.

15. Lake BG: Coumarin metabolism, toxicity and carcinogenicity: relevance for human risk assessment. Food Chem Toxicol 37: 423-453, 1999.

16. Jiménez-Orozco FA, López-González JS, Nieto-Rodriguez A, Velasco-Velázquez MA, Molina-Guarneros JA, MendozaPatiño N, García-Mondragón MJ, Elizalde-Galvan P, LeónCedeño F and Mandoki JJ: Decrease of cyclin D1 in the human lung adenocarcinoma cell line A-427 by 7-hydroxycoumarin. Lung Cancer 34: 185-194, 2001.

17. Marshall ME, Ryles M, Butler K and Weiss L: Treatment of advanced renal cell carcinoma (RCC) with coumarin and cimetidine: long term follow up of patients on a phase I trial. J Cancer Res Clin Oncol 120: 535-538, 1994.

18. Lopez-Gonzalez JS, Prado-Garcia H, Aguilar-Cazares D, Molina-Guarneros JA, Morales-Fuentes J and Mandoki JJ: Apoptosis and cell cycle disturbances induced by coumarin and 7-hydroxycoumarin on human lung carcinoma cell lines. Lung Cancer 43: 275-283, 2004.

19. Elinos-Báez CM, León F and Santos E: Effects of coumarin and $7 \mathrm{OH}$-coumarin on bcl-2 and Bax expression in two human lung cancer cell lines in vitro. Cell Biol Int 29: 703-708, 2005.

20. Finn GJ, Kenealy E, Creaven BS and Egan DA: In vitro cytotoxic potential and mechanism of action of selected coumarins, using human renal cell lines. Cancer Lett 183: 61-68, 2002.

21. Finn GJ, Creaven B and Egan D: Modulation of mitogenactivated protein kinases by 6-nitro-7-hydroxycoumarin mediates apoptosis in renal carcinoma cells. Eur J Pharmacol 481: 159-167, 2003.

22. Finn GJ, Creaven BS and Egan DA: Daphnetin induced differentiation of human renal carcinoma cells and its mediation by p38 mitogen-activated protein kinase. Biochem Pharmacol 67: 1779-1788, 2004.

23. Wang CJ, Hsieh YJ, Chu CY, Lin YL and Tseng TH: Inhibition of cell cycle progression in human leukemia HL-60 cells by esculetin. Cancer Lett 183: 163-168, 2002.

24. Yim D, Singh RP, Agarwal C, Lee S, Chi H and Agarwal R: A novel anticancer agent, decursin, induces G1 arrest and apoptosis in human prostate carcinoma cells. Cancer Res 65: 1035-1044, 2005.

25. Valenciennes E, Smadja J and Conan JY: Screening for biological activity and chemical composition of Euodia borbonica var. borbonica (Rutaceae), a medicinal plant in Reunion Island. J Ethnopharmacol 64: 283-288, 1999.

26. Salvatore A, Borkosky S, Willink E and Bardòn A: Toxic effects of lemon peel constituents on Ceratitis capitata. J Chem Ecol 30: 323-333, 2004.

27. Kawaii S, Tomono Y, Katase E, Ogawa K and Yano M: Isolation of furocoumarins from bergamot fruits as HL-60 differentiation-inducing compounds. J Agric Food Chem 47: 4073-4078, 1999. 
28. Glowniak K, Mroczek T, Zabza A and Cierpicki T: Isolation and structure elucidation of 5,7-disubstituted simple coumarins in the fruits of Heracleum mantegazzianum. Pharm Biol 38: 308-312, 2000.

29. Gao Y, Huang H, Xu H, Diao Y and Dong Z: Studies on the chemical constituents of Citrus medica var. sarcodactylis. Zhong Yao Cai 25: 639-640, 2002.

30. Canini A, Alesiani D, D'Arcangelo G and Tagliatesta P: Gas chromatography-mass spectrometry analysis of phenolic compounds from Carica papaya L. leaf. J Food Comp Anal 20: 584-590, 2007.

31. Prince M, Campbell CT, Robertson TA, Wells AJ and Kleiner HE: Naturally occurring coumarins inhibit 7,12-dimethylbenz[a]anthracene DNA adduct formation in mouse mammary gland. Carcinogenesis 27: 1204-1213, 2006.

32. Leszczyniecka M, Roberts T, Dent P, Grant S and Fisher PB: Differentiation therapy of human cancer: basic science and clinical applications. Pharmacol Ther 90: 105-156, 2001.

33. Pearson G, Robinson F, Beers Gibson T, Xu BE, Karandikar M, Berman $\mathrm{K}$ and Cobb MH: Mitogen-activated protein (MAP) kinase pathways: regulation and physiological functions. Endocr Rev 22: 153-183, 2001.

34. Fang JY and Richardson BC: The MAPK signalling pathways and colorectal cancer. Lancet Oncol 6: 322-327, 2005.

35. Jiang H, Lin J, Su ZZ, Collart FR, Huberman E and Fisher PB: Induction of differentiation in human promyelocytic HL-60 leukemia cells activates $\mathrm{p} 21$, WAF1/CIP1, expression in the absence of p53. Oncogene 9: 3397-3406, 1994.

36. Mosmann T: Rapid colorimetric assay for cellular growth and survival: application to proliferation and cytotoxicity assays. J Immunol Methods 65: 55-63, 1983.

37. Hill SE, Buffey J, Thody AJ, Oliver I, Bleehen SS and Mac NS: Investigation of the regulation of pigmentation in alphamelanocyte-stimulating hormone responsive and unresponsive cultured B16 melanoma cells. Pigment Cell Res 2: 161-166, 1989.

38. Bradford MM: A rapid and sensitive method for the quantitation of microgram quantities of protein utilizing the principle of protein-dye binding. Anal Biochem 72: 248-254, 1976.

39. Jabbar SA, Twentyman PR and Watson JV: The MTT assay underestimates the growth inhibitory effects of interferons. Br J Cancer 60: 523-528, 1989.

40. Umek RM, Friedman AD and McKnight SL: CCAAT-enhancer binding protein: a component of a differentiation switch. Science 251: 288-292, 1991 .

41.Zermati Y, Fichelson S, Valensi F, Freyssinier JM, Rouyer-Fessard P, Cramer E, Guichard J, Varet B and Hermine $\mathrm{O}$ : Transforming growth factor inhibits erythropoiesis by blocking proliferation and accelerating differentiation of erythroid progenitors. Exp Hematol 28: 885-894, 2000.

42. Schoenfeld N, Mamet R, Nordenberg Y, Shafran M, Babushkin T and Malik Z: Protoporphyrin biosynthesis in melanoma B16 cells stimulated by 5-aminolevulinic acid and chemical inducers: characterization of photodynamic inactivation. Int J Cancer 56: 106-112, 1994.

43. Ickowicz Schwartz DI, Gozlan Y, Greenbaum L, Babushkina T, Katcoff DJ and Malik Z: Differentiation-dependent photodynamic therapy regulated by porphobilinogen deaminase in B16 melanoma. Br J Cancer 90: 1833-1841, 2004.

44. Edward M, Gold JA and Mackie RM: Different susceptibilities of melanoma cell to retinoic acid-induced changes in melanotic expression. Biochem Biophys Res Commun 155: 773-778, 1988.

45. Pagliacci MC, Spinozzi F, Migliorati G, Fumi G, Smacchia M, Grignani F, Riccardi C and Nicoletti I: Genistein inhibits tumour cell growth in vitro but enhances mitochondrial reduction of tetrazolium salts: a further pitfall in the use of the MTT assay for evaluating cell growth and survival. Eur J Cancer 29A: 1573-1577, 1993.

46. Agarwal C, Sharma Y, Zhao J and Agarwal R: A polyphenolic fraction from grape seeds causes irreversible growth inhibition of breast carcinoma MDA-MB468 cells by inhibiting mitogenactivated protein kinases activation and inducing G1 arrest and differentiation. Clin Cancer Res 6: 2921-2930, 2000.
47. Medrano EE, Im S, Yang F and Abdel-Malek ZA: Ultraviolet B light induces G1 arrest in human melanocytes by prolonged inhibition of retinoblastoma protein phosphorylation associated with long-term expression of the p21Waf-1/SDI-1/Cip-1 protein. Cancer Res 55: 4047-4052, 1995.

48. Kato JY, Matsuoka M, Polyak K, Massaque J and Sherr CJ: Cyclic AMP-induced G1 phase arrest mediated by an inhibitor (p27Kip1) of cyclin-dependent kinase 4 activation. Cell 79: 487-496, 1994.

49. Nordenberg J, Albukrek D, Hadar T, Fux A, Wasserman L, Novogrodsky A and Sidi Y: Novobiocin-induced anti-proliferative and differentiating effects in melanoma B16. Br J Cancer 65: 183-188, 1992.

50. Finn GJ, Creaven BS and Egan DA: Activation of mitogen activated protein kinase pathways and melanogenesis by novel nitro-derivatives of 7-hydroxycoumarin in human malignant melanoma cells. Eur J Pharm Sci 26: 16-25, 2005.

51. Ortel B, Chen N, Brissette J, Dotto GP, Maytin E and Hasan T: Differentiation-specific increase in ALA-induced protoporphyrin IX accumulation in primary mouse keratinocytes. Br J Cancer 77: 1744-1751, 1998.

52. Sato N, Moore BW, Keevey S, Drazba JA, Hasan T and Maytin EV: Vitamin D enhances ALA-induced protoporphyrin IX production and photodynamic cell death in 3-D organotypic cultures of keratinocytes. J Investig Dermatol 127: 925-934, 2006.

53. Siboni G, Amit-Patito I, Weizman E, Waintraub-Porat M, Weitman H, Ehrenberg B and Malik Z: Specificity of photosensitizer accumulation in undifferentiated versus differentiated colon carcinoma cells. Cancer Lett 196: 57-64, 2003.

54. Sinha AK, Anand S, Ortel BJ, Chang Y, Mai Z, Hasan T and Maytin EV: Methotrexate used in combination with aminolaevulinic acid for photodynamic killing of prostate cancer cells. Br J Cancer 95: 485-495, 2006.

55. Iinuma S, Farshi SS, Ortel B and Hasan T: A mechanistic study of cellular photodestruction with 5-aminolaevulinic acid-induced porphyrin. Br J Cancer 70: 21-28, 1994.

56. Torii S, Yamamoto T, Tsuchiya Y and Nishida E: ERK MAP kinase in $\mathrm{G}_{1}$ cell cycle progression and cancer. Cancer Sci 97: 697-702, 2006.

57. Henson ES and Gibson SB: Surviving cell death through epidermal growth factor (EGF) signal transduction pathways: implications for cancer therapy. Cell Signal 18: 2089-2097, 2006.

58. Namkoong J, Martino JJ and Chen S: From existing therapies to novel targets: a current view on melanoma. Front Biosci 11: 2081-2092, 2006

59. Panka DJ, Atkins MB and Mier JW: Targeting the mitogenactivated protein kinase pathway in the treatment of malignant melanoma. Clin Cancer Res 12: 2371-2375, 2006.

60. Mansky KC, Sankar U, Han J and Ostrowski MC: Microphthalmia transcription factor is a target of the p38 MAPK pathway in response to receptor activator of NF-kappa B ligand signaling. J Biol Chem 277: 11077-11083, 2002.

61. Vance KW and Goding CR: The transcription network regulating melanocyte development and melanoma. Pigment Cell Res 17: 318-325, 2004.

62. Hearing VJ and Jimenez M: Analysis of mammalian pigmentation at molecular levels. Pigment Cell Res 2: 75-85, 1989.

63. Englaro W, Bertolotto C, Buscà R, Brunet A, Pagès G, Ortonne JP and Ballotti R: Inhibition of the mitogen-activated protein kinase pathway triggers B16 melanoma cell differentiation. J Biol Chem 273: 9966-9970, 1998.

64. Kadekaro AL, Kavanagh RJ, Wakamatsu K, Ito S, Pipitone MA and Abdel-Malek ZA: Cutaneous photobiology. The melanocyte vs. the sun: who will win the final round? Pigment Cell Res 16: 434-447, 2003.

65. Ignarro LJ, Ballot B and Wood KS: Regulation of soluble guanylate cyclase activity by porphyrins and metalloporphyrins. J Biol Chem 259: 6201-6207, 1984.

66. Brechler V, Pavoine C, Hanf R, Garbarz E, Fischmeister R and Pecker F: Inhibition by glucagon of the cGMP-inhibited low-Km cAMP phosphodiesterase in heart is mediated by a pertussis toxin-sensitive G-protein. J Biol Chem 267: 15496-15501, 1992 . 